\title{
Caracterização e avaliação de fatores que determinam a remoção de microcistina-LR em carvão ativado granular produzido a partir de diferentes matérias-primas
}

Characterization and evaluation of factors influencing microcystin- $L R$ removal by granular activated carbon produced from different raw materials

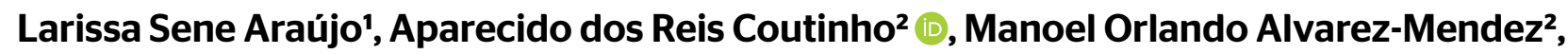
Rodrigo Braga Moruzzi ${ }^{3 *}$ (1), Maria do Carmo Calijuri' ${ }^{(1)}$, Davi Gasparini Fernandes Cunha' ${ }^{(1)}$

\begin{abstract}
RESUMO
As microcistinas (MC), que estão entre as cianotoxinas mais encontradas em florações de cianobactérias, não são eficientemente removidas pelas tecnologias do ciclo completo de tratamento de água. Como barreira adicional para sua remoção, destaca-se o processo de adsorção com carvão ativado granular (CAG). Esta pesquisa comparou a eficiência de remoção de MC-LR por sete CAG produzidos a partir de diferentes matérias-primas, analisando as propriedades das amostras: umidade, teor de cinzas, pH e características texturais. Inicialmente, os resultados indicaram que as propriedades dos CAG foram influenciadas pelo material de origem, assim como pelo método de produção. Nos ensaios de adsorção, o modelo de Langmuir indicou que, em quatro horas, com dosagem de 100 mg.'ㄴ.1, o CAG de linhito (CGLIN) apresentou a maior capacidade de remoção (97,2\%) de MC-LR (C : 115,1 $\left.\mu \mathrm{g} . \mathrm{L}^{-1}\right)$, com q $\mathrm{q}_{\text {emáx }}$ de 10,6 mg.g'. O volume de mesoporos influenciou significativamente a capacidade adsortiva de MC dos carvões avaliados ( $r=0,98$, Pearson). Esses resultados podem oferecer subsídios para a aplicação do processo de adsorção de MC-LR em estações de tratamento de água (ETA) para a minimização de intoxicações por água contaminada.

Palavras-chave: carvão ativado; adsorção; microcistina-LR; tratamento avançado de água.
\end{abstract}

\begin{abstract}
Microcystins (MC), which are among the cyanotoxins more commonly found in cyanobacterial blooms, are not efficiently removed by fullcycle water treatment technologies. As an additional barrier, there is the adsorption process with granular activated carbon (GAC). This research compared the efficiency of MC-LR removal by seven GACs produced from different raw materials, analyzing these samples' properties: moisture, ash content, $\mathrm{pH}$ and textural characteristics. Initially, the results indicated that the GAC properties were influenced by the source material, as well as by the production method. In the adsorption assays, the Langmuir model indicated that in 4h, with $100 \mathrm{mg} \mathrm{L}^{-1}$ dosage, the granular activated carbon of lignite (CGLIN) had the highest MC-LR ( $\left.C_{0}: 115.1 \mu \mathrm{g} . \mathrm{L}^{-1}\right)$ removal capacity (97.2\%), with $q_{e \text { max }}$ of 10.6 mg.g. The volume of mesopores significantly influenced the adsorption capacity of microcystin by the evaluated GACs $(r=0.98$, Pearson). These results can support the application of the MC-LR adsorption process in water treatment plants to minimize intoxication with contaminated water.
\end{abstract}

Keywords: activated carbon; adsorption; microcystin-LR; advanced water treatment.

\section{INTRODUÇÃO}

Estudos sobre a estrutura e o funcionamento dos ecossistemas aquáticos continentais (e.g., rios, lagos e reservatórios) têm relatado o aumento da vulnerabilidade desses ambientes diante das diversas atividades antrópicas que acarretam alterações em sua condição natural (PETERS
\& MEYBECK, 2000). Tais atividades contribuem para o processo de eutrofização devido ao aporte excessivo de nutrientes, sobretudo fósforo e nitrogênio. O excesso desses nutrientes, quando combinado a outras condições ambientais (e.g., disponibilidade de luz, temperatura normalmente entre $15-30^{\circ} \mathrm{C}$, além do regime dos ventos), acelera o crescimento de algas, cianobactérias e plantas aquáticas, comprometendo os 
usos múltiplos da água. As cianobactérias são organismos procariontes fotossintetizantes, de alta capacidade adaptativa, com algumas espécies potencialmente tóxicas (CHORUS, 2001; WOOD, 2016). A produção de cianotoxinas pode estar relacionada com a própria condição de crescimento das cianobactérias, com a competição por recursos e com a proteção contra seus predadores primários (zooplâncton) (CALIJURI; ALVES; SANTOS, 2006).

As microcistinas (MC) são cianotoxinas hepatotóxicas cíclicas produzidas por cianobactérias dos gêneros Microcystis, Anabaena, Nodularia, Cylindrospermopsis e Aphanizomenon, entre outros. O gênero Microcystis é o mais conhecido e globalmente estudado quanto à produção de MC (HARKE et al., 2016). De acordo com a sua composição química, a MC pode apresentar diferentes variantes no meio, como MC-LR (leucina-arginina), MC-RR (arginina-arginina), MC-YA (tirosina-alanina) e MC-LA (leucina-alanina). A MC-LR é considerada a mais tóxica entre as mais de 90 variantes conhecidas (USEPA, 2014).

As intoxicações por MC podem ser agudas ou crônicas e provocar sintomas como diarreia, vômito, fraqueza, palidez e até mesmo morte por choque hemorrágico. Isso ocorre porque a MC desregula o fluxo sanguíneo e inibe as proteínas fosfatases que controlam as atividades celulares do fígado (MARTINS \& VASCONCELOS, 2009). Diante desses efeitos, a Portaria de Consolidação nº 5/2017 (BRASIL, 2017) estabeleceu o valor máximo permitido (VMP) de MC em 1,0 $\mu \mathrm{g} . \mathrm{L}^{-1}$ para água potável, conforme recomenda a Organização Mundial da Saúde (WHO, 2011).

Eventos de intoxicações por MC no Brasil foram descritos nos trabalhos de Teixeira et al. (1993), Carmichael et al. (2001) e Hilborn et al. (2013). Em países como Estados Unidos, Austrália, Canadá, China, Suécia (CARMICHAEL, 2000) e Argentina (GIANNUZZI et al., 2011), entre os anos de 1931 e 2007, também foram relatadas intoxicações agudas por cianotoxinas. Essas ocorrências permitem alocar as cianotoxinas na categoria de poluentes emergentes (SAUVÉ \& DESROSIERS, 2014), assim como fármacos e cosméticos, também denominados contaminantes de terceira geração. Esses contaminantes são de difícil remoção por meio dos processos convencionais de tratamento de água, como coagulação, floculação, sedimentação e filtração (DURIGAN; VAZ; PERALTA-ZAMORA, 2012).

Assim, para a garantia da saúde pública, tem sido estudada a aplicação de tecnologias complementares àquelas do tratamento de ciclo completo das estações de tratamento de água (ETA). Entre as tecnologias de tratamento avançado para a remoção de cianotoxinas, destaca-se o processo de adsorção, caracterizado pela retenção e acumulação de certas substâncias líquidas ou gasosas (adsorvatos) na superfície de um sólido: o adsorvente (LETTERMAN, 1999; REYNOLDS \& RICHARDS, 1995). O carvão ativado (CA) é o adsorvente mais empregado e eficiente no tratamento de água por adsorver compostos que causam gosto, odor, cor, mutagenicidade e toxicidade à água (LETTERMAN, 1999; REYNOLDS \& RICHARDS, 1995).
O CA comercial é normalmente obtido a partir de matérias-primas de origem natural e renováveis (madeira, fibras, cascas, caroços etc.), de origem mineral (antracito, carvão mineral, coque de petróleo etc.) ou sintética (fibras rayon, PAN-poliacrilonitrila etc.). Alternativamente, os CA podem ser produzidos a partir de materiais com elevado teor de carbono e baixo custo, como os resíduos agrícolas, com destaque para o bagaço de cana-de-açúcar, endocarpo e mesocarpo de coco seco, resíduo da madeira (de pínus, eucalipto etc.), casca de macadâmia, caroços de abacate e de açaí, entre outros (ALBUQUERQUE JÚNIOR et al., 2008a; 2008b; 2008c; COSTA et al., 2012; MÉNDEZ et al., 2006; RODRIGUES et al., 2011). A produção de CA é realizada por meio de dois processos principais: carbonização (ou pirólise) e ativação (ou oxidação). O CA pode ser produzido em forma de pó (CAP) ou granular (CAG).

A capacidade adsortiva do CA está ligada à estrutura, ao volume, ao tamanho e à distribuição de tamanho de poros. De acordo com o tamanho dos poros, segundo a International Union of Pure and Applied Chemistry (IUPAC), os CA são classificados em microporo (<2 nm), mesoporo (20-50 nm) e macroporo (>50 nm) (LAMBERT; HOLMES; HRUDEY, 1996). A capacidade de adsorção do CA também está ligada à reatividade dos diferentes elementos químicos que compõem a estrutura do material. Adicionalmente, as características do adsorvato, como sua massa molecular e os grupos funcionais de sua molécula, também influenciam a eficiência da adsorção. Igualmente importantes são as condições experimentais, que incluem $\mathrm{pH}$, temperatura, tempo de contato entre adsorvente e adsorvato, agitação e a presença de compostos em água que podem competir por sítios de adsorção (KURODA et al., 2005; REALI; SABOGAL-PAZ; DANIEL, 2013).

Com base nesses conceitos, a presente pesquisa, de caráter experimental, foi realizada em escala de laboratório a fim de avaliar o desempenho de carvões ativados produzidos a partir de diferentes matérias-primas na remoção de MC-LR, analisando as características dos materiais adsorventes e buscando correlações dessas propriedades com a eficiência de remoção do poluente-alvo.

\section{METODOLOGIA}

\section{Obtenção do extrato de microcistina-LR e preparação da água de estudo}

O extrato de MC-LR foi preparado por meio do cultivo de cepa tóxica de Microcystis aeruginosa (código BB005) por Ortolan (2016), isolada a partir do reservatório de Barra Bonita, em São Paulo, e depositada na Coleção de Cultura de Microalgas (WDCM835) da Universidade Federal de São Carlos (UFSCar). O cultivo foi realizado em meio WC, fotoperíodo de 12 horas, temperatura de $24 \pm 1^{\circ} \mathrm{C}$, sob aeração e intensidade luminosa de $60 \mu \mathrm{E} \cdot \mathrm{m}^{-2} \cdot \mathrm{s}^{-1}$, em fotobiorreator aeróbio de aproximadamente $160 \mathrm{~L}$, sem condições de assepsia. 
Decorridos 30 dias de crescimento, a cultura passou pelo processo proposto por Törökné et al. (2004) e Yilmaz et al. (2008) de congelamento e descongelamento (quatro vezes) para a lise celular das cianobactérias eliberação da MC intracelular no meio (ORTOLAN, 2016). Em seguida, a solução foi centrifugada por 10 minutos, a $11.000 \mathrm{rpm}$ e $4^{\circ} \mathrm{C}$. A concentração de MC-LR na amostra centrifugada e utilizada nos ensaios foi estimada pelo método do Ensaio de Imunoadsorção Enzimática (Enzyme-Linked Immunosorbent Assay — ELISA) com kit em placa Beacon (limite de detecção: 0,1 $\mu \mathrm{g} \cdot \mathrm{L}^{-1}$ ).

A água de estudo foi preparada a partir da diluição do extrato centrifugado com água deionizada para concentração inicial próxima a 100,0 $\mu \mathrm{g} . \mathrm{L}^{-1}$ de MC-LR.

\section{Caracterização dos carvões ativados granulares}

Foram selecionadas sete amostras de CAG para o presente estudo (Tabela 1), sendo cinco disponíveis comercialmente por fabricantes com unidades no Brasil ou nos Estados Unidos e outros dois produzidos no Laboratório de Materiais Carbonosos (LMC) da Universidade Metodista de Piracicaba (UNIMEP), campus Santa Bárbara d'Oeste (SP).

Os CA foram caracterizados por meio dos parâmetros teor de umidade; teor de cinzas (TC); pH; área superficial específica (ASE); e distribuição, tamanho/diâmetro e volume dos poros. A quantificação da umidade seguiu, com adaptações, a NBR 12.077 (MB 3.414), de 1991 (ABNT, 1991a, 1991b). O TC e o pH das amostras foram medidos com base na norma Japanese Industrial Standard (JIS) K 1.474/2014.

Por meio da análise da adsorção de gás nitrogênio $\left(\mathrm{N}_{2}\right)$ a $77 \mathrm{~K}$ realizada no equipamento Autosorb-1MP (Quantachrome Corporation) do LMC, foi possível obter a isoterma de adsorção de nitrogênio para os materiais selecionados. Os dados da isoterma foram ajustados ao modelo de adsorção Brunauer, Emmett e Teller (BET) (Equação 1) para determinação da ASE das amostras. A distribuição do tamanho dos poros das amostras foi obtida ajustando os dados da isoterma ao modelo de adsorção non-Local Density Function Theory (nLDFT). Os valores de volume e área dos microporos foram determinados por meio do método gráfico t-plot, empregando carbon black como referência para a determinação da espessura estatística da camada adsorvida.

Tabela 1 - Origem dos carvões ativados granulares avaliados para remoção de microcistina de água de abastecimento em laboratório.

\begin{tabular}{c|c|c} 
Fabricante & Matéria-prima & Nomenclatura \\
\multirow{2}{*}{$\mathrm{A}$} & Linhito* $^{*}$ & CGLIN \\
\hline \multirow{2}{*}{$B$} & Hulha betuminosa & CGHU \\
\cline { 2 - 3 } & Casca de coco & CGCO1 \\
\hline C & Casca de coco & CGCO2 \\
\hline D & Casca de coco & CGCO3 \\
\hline \multirow{2}{*}{$L M C$} & Casca de coco & CGCO4 \\
\cline { 2 - 3 } & Casca de macadâmia & CGMAC \\
\hline
\end{tabular}

LMC: Laboratório de Materiais Carbonosos (UNIMEP).

*CAG produzido em Marshall, Texas, Estados Unidos.
$\mathrm{V}_{\mathrm{a}}=\frac{\mathrm{V}_{\mathrm{m}} \cdot \mathrm{C} \cdot \mathrm{P}}{\left(\mathrm{P}_{0}-\mathrm{P}\right)\left[1+(\mathrm{C}-1) \cdot \frac{\mathrm{P}}{\mathrm{P}_{0}}\right]}$

Em que:

$\mathrm{V}_{\mathrm{a}}=$ volume de gás adsorvido na pressão $\mathrm{P}(\mathrm{mL})$;

$\mathrm{V}_{\mathrm{m}}=$ volume de gás adsorvido quando toda a superfície está coberta por uma camada monomolecular $(\mathrm{mL})$;

$\mathrm{C}=$ constante relacionada com o calor de adsorção;

$\mathrm{P}=$ pressão de equilíbrio do gás adsorvido $(\mathrm{Pa})$;

$\mathrm{P}_{\mathrm{o}}=$ pressão de saturação do gás $(\mathrm{Pa})$.

\section{Avaliação da capacidade adsortiva e análise estatística}

A avaliação da capacidade adsortiva dos carvões sobre MC-LR seguiu a norma American Society for Testing and Materials (ASTM) D 3860/2014, divindo-se em duas fases. Para esses ensaios, os carvões foram moídos e peneirados em peneira ABNT $48(300 \mu \mathrm{m})$.

\section{Fase 1: tempo de equilíbrio}

Inicialmente, determinou-se o tempo de equilíbrio (TE) entre as amostras de CA e a água de estudo por meio de testes de 1, 2, 4, 8 e 24 horas. A concentração inicial de MC-LR (C $)$ foi de 108,8 a 197,4 $\mu$ g.L-1 e o pH variou de 7,4 a 7,6. Os testes foram realizados em temperatura ambiente de $24,5 \pm 0,4^{\circ} \mathrm{C}$, com dosagem fixa para cada carvão $\left(10,20\right.$ ou $\left.50 \mathrm{mg} . \mathrm{L}^{-1}\right)$. Testes prévios indicaram diferentes capacidades adsortivas das amostras de carvão, que levaram à necessidade de adoção de dosagens distintas para que fosse possível determinar o TE para cada caso. Após ser mantida sob agitação de $200 \mathrm{rpm}$ nos tempos testados, a mistura de $100 \mathrm{~mL}$ foi filtrada à vácuo em membranas de nylon $(0,45 \mu \mathrm{m})$ para remoção do adsorvente e quantificação da toxina pelo método do ELISA.

\section{Fase 2: isotermas de adsorção}

Fixado o TE, novos experimentos foram realizados, em temperatura ambiente de $27,1 \pm 0,9^{\circ} \mathrm{C}\left(\mathrm{C}_{\mathrm{o}}: 81,9\right.$ a 154,9 $\mu \mathrm{g} . \mathrm{L}^{-1} ; \mathrm{pH}: 7,2$ a 7,7), com variação da dosagem de carvão de 5,0 a 375,0 mg.L. $\mathrm{L}^{-1}$ em um volume total de mistura de $200 \mathrm{~mL}$. As dosagens foram variadas para verificar a relação do aumento da adsorção com o aumento de massa. Foram seguidas as mesmas condições de agitação, filtração, armazenamento e quantificação da toxina da fase anterior.

Para determinar a capacidade adsortiva dos carvões, os resultados experimentais foram ajustados às isotermas descritas pelos modelos de adsorção de Langmuir (Equação 2) e de Freundlich (Equação 3).

$\mathrm{q}_{\mathrm{e}}=\frac{\mathrm{q}_{\text {máx }} \cdot \mathrm{b} \cdot \mathrm{C}_{\mathrm{e}}}{1+\mathrm{b} \cdot \mathrm{C}_{\mathrm{e}}}$

Em que:

$\mathrm{q}_{\mathrm{e}}=$ massa de adsorvato por unidade de adsorvente ( $\left.\mathrm{mg}^{\mathrm{g}} \mathrm{g}^{-1}\right)$;

$\mathrm{q}_{\text {máx }}=$ quantidade máxima adsorvida pelo adsorvente no equilíbrio (parâmetro de ajuste do modelo); 
$\mathrm{b}=$ parâmetro de afinidade adsorvente/adsorvato do modelo de Langmuir (parâmetro de ajuste do modelo);

$\mathrm{C}_{\mathrm{e}}=$ concentração de adsorvato no equilíbrio (mg. $\mathrm{L}^{-1}$ ou mol. $\left.\mathrm{L}^{-1}\right)$.

$\mathrm{q}_{\mathrm{e}}=\mathrm{K}_{\mathrm{ad}} \cdot \mathrm{C}_{\mathrm{e}}^{1 / \mathrm{n}}$

As constantes dadas por $\mathrm{K}_{\mathrm{ad}}$ e $1 / \mathrm{n}$ são dependentes da temperatura e são parâmetros de ajustes empíricos do modelo de Freundlich.

Adicionalmente, os resultados foram modelados empiricamente visando interpretar o processo de decaimento da concentração de toxina com o aumento das dosagens de CAG por meio de ajustes linear e exponencial.

Utilizou-se o coeficiente de correlação de Pearson (r) para análise das correlações entre as características dos CAG entre si e sua capacidade de adsorção de MC-LR.

\section{RESULTADOS E DISCUSSÃO}

\section{Caracterização dos carvões ativados}

$\mathrm{Na}$ fase de caracterização, todos os CAG à base de casca de coco apresentaram teor de umidade acima do limite de $8 \%$ da American Water Works
Association (AWWA) B604/2012 (Figura 1A) (BRADY \& MORAN, 2012). Essa semelhança de resultados indica que a matéria-prima pode influenciar na capacidade de impregnação de vapor-d'água no material ativado.

Elevado TC (Figura 1B) foi observado para os CAG de linhito (CGLIN) (15\%) e CAG de hulha betuminosa (CGHU) (14\%), indicando maior porcentagem de resíduos (impurezas inorgânicas), propriedade inerente à característica mineral da matéria-prima. Essas impurezas, que resultam da pirólise do material ativado (ZAGO, 2010), por consequência, reduzem sua capacidade adsortiva. Esses resultados indicam, portanto, que os CAG de origem mineral apresentaram maior proporção de inorgânicos (TC) que os de origem de biomassa. Os valores de TC semelhantes dos CAG produzidos no LMC (CAG de casca de coco 4 - CGCO4 - e CAG de casca de macadâmia - CGMAC) estão ligados ao uso do mesmo processo de produção. Isso porque, na carbonização e ativação, a aplicação de taxas de aquecimento específicas regula a taxa de queima do material, influenciando na formação de resíduos sem características ativas para a adsorção (DI BERNARDO \& DANTAS, 2005).

A maioria das amostras apresentou $\mathrm{pH}$ (Figura $1 \mathrm{C}$ ) próximo à neutralidade $(6,1$ a 7,7$)$. O menor valor de $\mathrm{pH}(5,6)$ do CGLIN é justificado pela lavagem ácida feita nesse $\mathrm{CA}$ ao fim do processo produtivo,

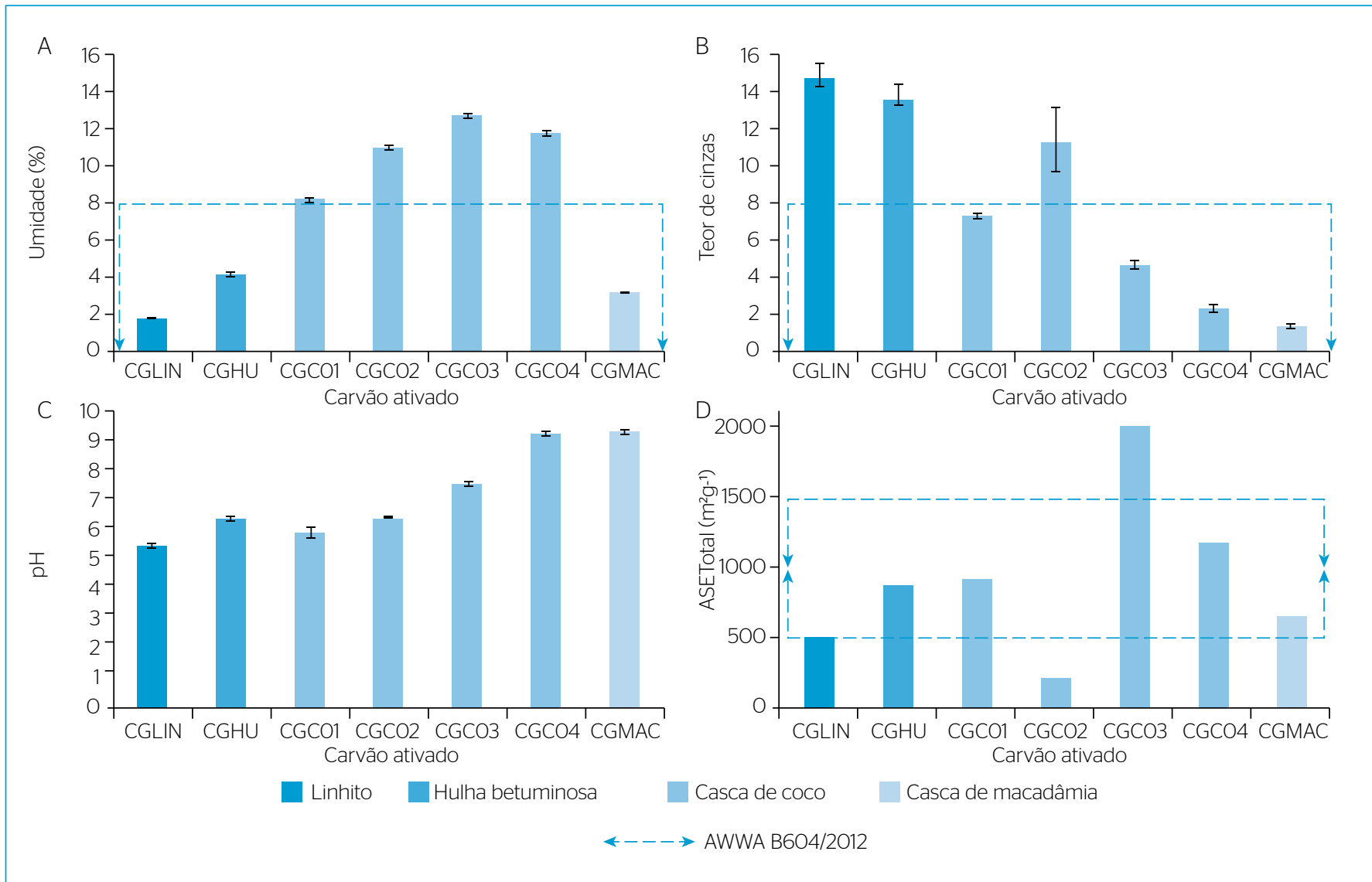

Figura 1 - Caracterização das amostras de carvão ativado quanto a (A) umidade, (B) teor de cinzas, (C) pH e (D) área superficial específica total. 
segundo informado pelo Fabricante A. Os CA produzidos no LMC (CGCO4 e CGMAC) apresentaram valores semelhantes de pH $(9,4$ e 9,5), indicando que o processo do laboratório induziu a formação de grupamentos químicos de natureza básica na superfície porosa. Martinez et al. (2011) encontraram valores de $\mathrm{pH}$ na faixa alcalina $(9,6)$ para CAG de babaçu e ressaltaram a importância desse parâmetro nas interações eletrostáticas que regem a adsorção. Huang, Cheng \& Cheng (2007) observaram aumento na adsorção de MC-LR com diminuição do $\mathrm{pH}$ de 8 para 3 testando três carvões comerciais.

O carvão granular comercial à base de casca de coco (CGCO3) apresentou a $\operatorname{ASE}_{\text {Total }}\left(2.010 \mathrm{~m}^{2} \cdot \mathrm{g}^{-1}\right)$ mais elevada (Figura 1D), seguido do CGCO4 (1.184 $\mathrm{m}^{2} \cdot \mathrm{g}^{-1}$ ) (Tabela 2). O CGLIN apresentou baixa porcentagem de ASE formada por microporos (32,5\%), com maior volume de mesoporos $\left(0,53 \mathrm{~cm}^{3} \cdot \mathrm{g}^{-1}\right)$, enquanto as demais amostras apresentaram elevado volume de microporos em sua estrutura (acima de 85\%). Donati et al. (1994) reforçaram que é raro encontrar CA com elevado volume de mesoporos, pois esses materiais são, em geral, essencialmente microporosos. Segundo critério estabelecido pela norma AWWA B604/2012, o carvão CAG de casca de coco 2 (CGCO2) estaria inadequado para a aplicação no tratamento de água (ASE $<500 \mathrm{~m}^{2} \cdot \mathrm{g}^{-1}$, Tabela 2)

Albuquerque Júnior et al. (2008a) reportaram valores de ASE (789,5 a $\left.1.079,5 \mathrm{~m}^{2} \cdot \mathrm{g}^{-1}\right)$ e mesoporos $\left(0,03 \mathrm{a} 0,20 \mathrm{~cm}^{3} \cdot \mathrm{g}^{-1}\right)$ variáveis para quatro CAG produzidos a partir de endocarpo de coco, mas com volumes de microporos semelhantes $\left(0,37 \mathrm{a} 0,46 \mathrm{~cm}^{3} \cdot \mathrm{g}^{-1}\right)$. Entre esses carvões, aquele com o maior valor de ASE e menor volume de microporos (maior volume de mesoporos) apresentou a maior capacidade de remoção de MC-LR. Os autores também observaram relação positiva entre elevada ASE (1.174,3 m2.g-1) e volume de mesoporos ( $51 \%$ do volume total) com a elevada remoção de MC-LR $(98,7 \%)$ por carvões à base de bagaço de cana-de-açúcar.
Na adsorção gasosa (Figura 2A), os carvões CGHU, CAG de casca de coco 1 (CGCO1), CAG de casca de coco 3 (CGCO3), CGCO4 e CGMAC apresentaram isoterma do Tipo I segundo a classificação da IUPAC (SING et al., 1985), que é característica de materiais microporosos. Os carvões CGLIN e CGCO2 apresentaram isoterma de Tipo IV (Figura 2B), característica de materiais mesoporosos e de superfícies desuniformes. Histerese do Tipo H4 (SING et al., 1985) foi observada na isoterma do carvão CGLIN, indicando poros semelhantes à forma cilíndrica. A leve histerese nas curvas do CGHU, CGCO3 e CGMAC indica geometria de poros entre cilíndricos e do tipo fenda. No entanto, o fenômeno não foi claramente visualizado e não se deve descartar a possível influência de imprecisões nas medidas ou no método utilizado. Nos demais casos (CGCO1, CGCO2 e CGCO4), a ausência da histerese sugere poros predominantemente do tipo fenda.

\section{Avaliação da capacidade adsortiva}

Na primeira fase, o TE de cada amostra de CA foi estimado pela relação entre a concentração remanescente de toxina em solução $\left(\mu \mathrm{g} \cdot \mathrm{L}^{-1}\right)$ e os tempos de contato testados (h) (Figura 3). Todos os carvões apresentaram maior adsorção de MC-LR nas primeiras horas testadas (uma, duas ou quatro horas), próximas ao tempo de duas horas descrito pela norma ASTM D3860/2014 como suficiente para atingir o estado de equilíbrio (ASTM, 2014). Com os TE fixados, na segunda fase de ensaios, com variação de massa de carvão (Tabela 3), a maioria dos dados se ajustou melhor ao modelo de Langmuir, assim como observado por Hena et al. (2014), que também estudaram a remoção de MC-LR. Esse comportamento pode indicar que, nos carvões, ocorre adsorção em monocamada (SING et al., 1985), tendo em vista que, segundo Zhu et al. (2016), o modelo de Langmuir assume que a

Tabela 2 - Propriedades texturais das amostras de carvão ativado calculadas a partir da isoterma de adsorção de $\mathrm{N}_{2}$ a $77 \mathrm{~K}$.

\begin{tabular}{|c|c|c|c|c|c|c|c|}
\hline Carvão & CGLIN & CGHU & CGCO1 & $\mathrm{CGCO} 2$ & $\mathrm{CGCO} 3$ & $\mathrm{CGCO} 4$ & CGMAC \\
\hline $\operatorname{ASE}_{\text {Total }}\left(m^{2} \cdot g^{-1}\right)$ & 503,5 & 881,4 & 938,0 & 224,8 & 2010,0 & 1184,0 & 646,5 \\
\hline $\operatorname{ASE}_{\text {micro }}\left(m^{2} \cdot g^{-1}\right)$ & 163,8 & 835,7 & 904,0 & 180,7 & 1933,0 & 1113,0 & 603,4 \\
\hline$\%_{\text {ASEmicro }}$ & 32,5 & 94,8 & 96,4 & 80,4 & 96,2 & 94,0 & 93,3 \\
\hline$V_{T P}\left(\mathrm{~cm}^{3} \cdot \mathrm{g}^{-1}\right)$ & 0,60 & 0,43 & 0,41 & 0,11 & 0,90 & 0,53 & 0,28 \\
\hline$V_{\text {micro }}\left(\mathrm{cm}^{3} \cdot \mathrm{g}^{-1}\right)$ & 0,08 & 0,37 & 0,36 & 0,07 & 0,78 & 0,45 & 0,24 \\
\hline$V_{\text {meso }}\left(\mathrm{cm}^{3} \cdot \mathrm{g}^{-1}\right)$ & 0,53 & 0,06 & 0,05 & 0,04 & 0,12 & 0,08 & 0,05 \\
\hline$\%_{\text {volmicro }}$ & 12,5 & 85,9 & 88,3 & 65,1 & 86,3 & 84,9 & 83,5 \\
\hline Formato do poro & Cilíndrico & $\begin{array}{l}\text { Cilíndrico e } \\
\text { fenda }\end{array}$ & Fenda & Fenda & $\begin{array}{l}\text { Cilíndrico e } \\
\text { fenda }\end{array}$ & Fenda & $\begin{array}{c}\text { Cilíndrico e } \\
\text { fenda }\end{array}$ \\
\hline $\mathrm{T}_{\text {modal }}(\mathrm{nm})$ & 1,69 & 1,23 & 1,23 & 1,61 & 1,23 & 1,30 & 1,18 \\
\hline $\mathrm{T}_{\text {médio }}(\mathrm{nm})$ & 4,80 & 1,96 & 1,73 & 1,98 & 1,80 & 1,78 & 1,76 \\
\hline Isoterma & IV & I & I & IV & I & 1 & I \\
\hline Histerese & Sim & Leve & Não & Não & Leve & Não & Leve \\
\hline
\end{tabular}

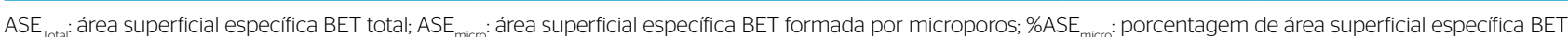
formada por microporos; $\mathrm{V}_{\mathrm{TP}}$ : volume total de poros; $\mathrm{V}_{\text {micro: }}$ : volume de microporos; $\mathrm{V}_{\text {meso: }}$ : volume de mesoporos $=\mathrm{V}_{\mathrm{TP}}-\mathrm{V}_{\text {micrio }} \%$ Vol $\mathrm{I}_{\text {micro }}$ : porcentagem de volume formado por microporos; $T_{\text {modal }}$ tamanho de poro predominante; $T_{\text {médio: }}$ tamanho de poro médio. 


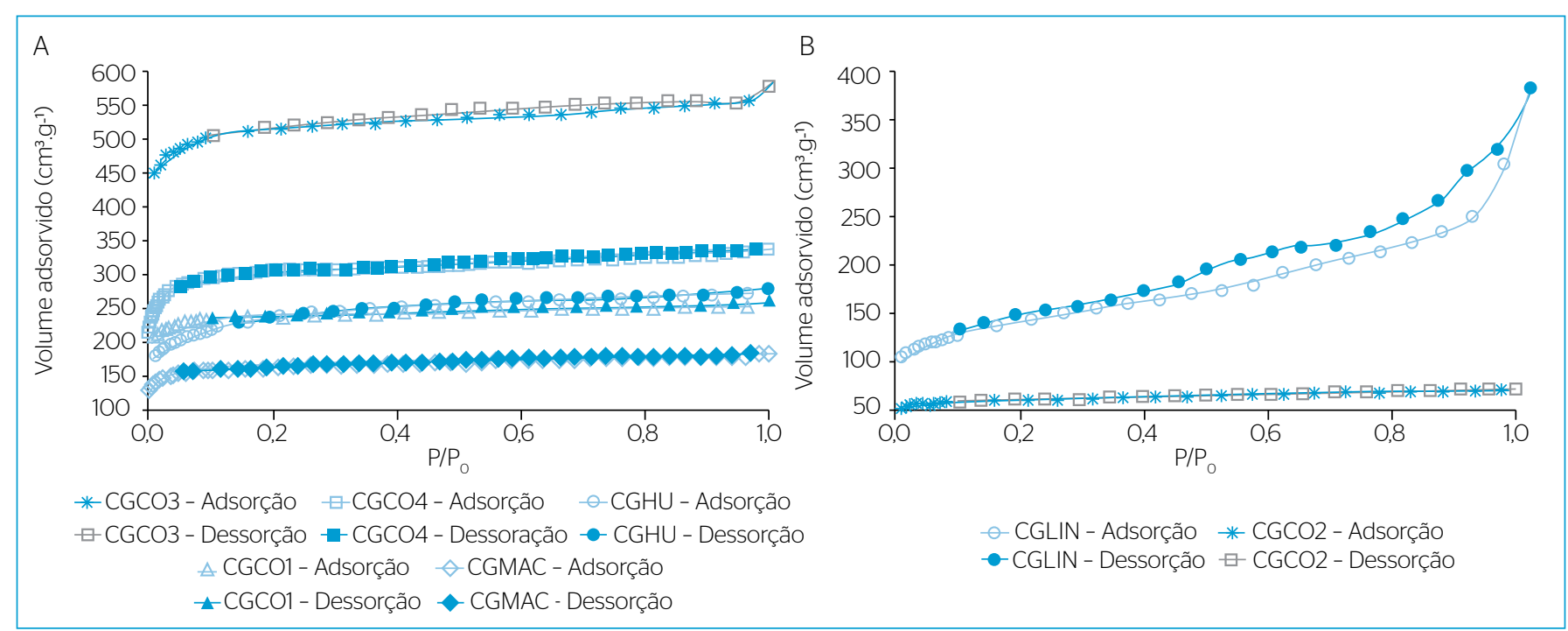

Figura 2 - Isotermas de adsorção e de dessorção de nitrogênio gasoso $\left(\mathrm{N}_{2}\right)$ a $77 \mathrm{~K}$ do Tipo (A) I e do (B) IV.

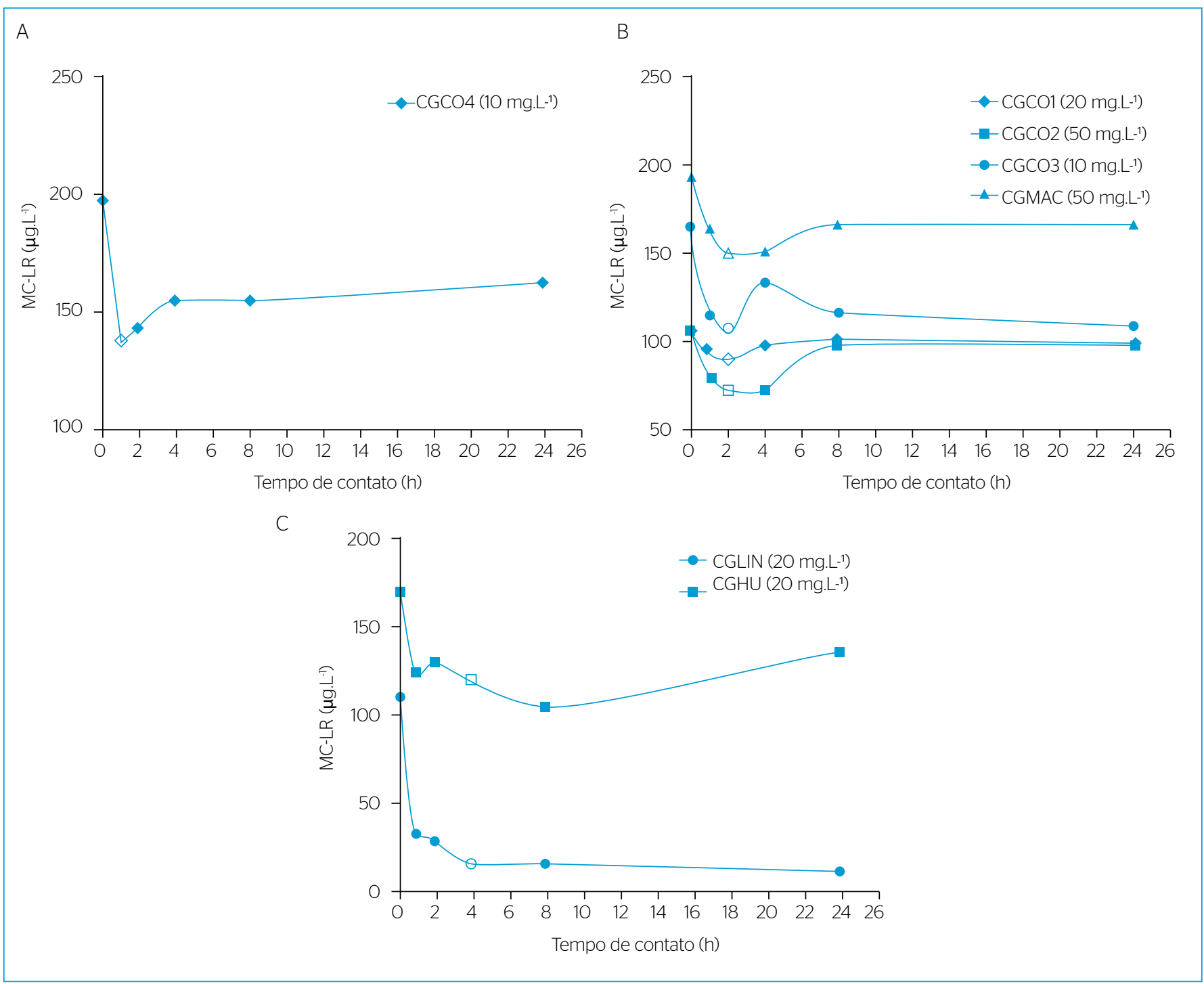

Figura 3 - Resultados dos ensaios de determinação do tempo de equilíbrio em (A) uma hora, (B) duas horas e (C) quatro horas. 
energia de adsorção se distribui uniformemente na superfície do adsorvente. O CGCO2 foi a única amostra com melhor ajuste ao modelo de Freundlich, o que indica sua maior irregularidade superficial, já que esse modelo descreve a energia de adsorção em superfícies mais heterogêneas (HENA et al., 2014).

Seguindo o modelo de Langmuir (Tabela 3), o CAG de linhito (CGLIN) apresentou a maior capacidade adsortiva, $\mathrm{q}_{\mathrm{e}, \text { máx }}(10,56 \mathrm{mg} \cdot \mathrm{g}$ ${ }^{1}$ ), na menor dosagem utilizada (100 mg.. $\left.\mathrm{L}^{-1}\right)$, com remoção de 97,2\%. Contudo, o CGCO3 apresentou maior energia de adsorção ligada à constante de Langmuir - $b$ (1519,0 L.mg $\left.{ }^{-1}\right)$, embora tenha apresentado $\mathrm{q}_{\text {e,máx }}$ abaixo de $1,0 \mathrm{mg} \cdot \mathrm{g}^{-1}$. Utilizando tempo de contato de 24 horas, Huang, Cheng \& Cheng (2007) descreveram valores de $\mathrm{q}_{e, \text { máx }}$ maiores para CAG de origem mineral e de casca de coco de 17,5 e 16,1 mg.g ${ }^{-1}$, respectivamente. Campinas \& Rosa (2006), ao estudarem CAP comercial com quatro horas de tempo de contato e $\mathrm{C}_{\mathrm{o}} 26 \mu \mathrm{gMC}$-LR.L ${ }^{-1}$, também encontraram maiores valores de $\mathrm{q}_{e, \text { máx }}$ e b: 13,0 mg.g ${ }^{-1}$ e 1800 L.mg-1, respectivamente. Donati et al. (1994) reportaram valores de $\mathrm{q}_{e, \text { máx }}$ muito variáveis (20 a $280 \mathrm{mg}^{-1} \mathrm{~g}^{-1}$ ) após testes com oito carvões de diferentes origens (hulha, coco, turfa e madeira). Essa diferença de capacidade deve considerar que, nos estudos de Donati et al. (1994), Campinas \& Rosa (2006) e Huang, Cheng \& Cheng (2007), foram realizados testes com extrato purificado de MC-LR e em água Milli-Q. Com isso, as menores $\mathrm{q}_{e, \text { máx }}$ da Tabela 3 possivelmente se devem aos compostos orgânicos de origem intracelular presentes no extrato bruto de toxina utilizado na presente pesquisa e que podem competir pelos sítios de adsorção.

Pendleton, Schumann \& Wong (2001), Hena et al. (2014) e Zhu et al. (2016) observaram melhora na capacidade de adsorção de MC-LR por CA com a diminuição do $\mathrm{pH}$ da solução para valores abaixo da neutralidade, o que pode justificar a boa capacidade adsortiva do CGLIN. O ajuste gráfico dos dados ao modelo de Langmuir (Figura 4) indica que a capacidade adsortiva é maior quanto mais horizontal e próxima ao eixo das abscissas for a isoterma, com $\mathrm{q}_{e, \text { máx }}$ inversamente proporcional ao coeficiente angular (Equação 2).
Nessas condições de ensaio, nenhuma das doses de CAG utilizadas foi suficiente para reduzir a concentração de MC-LR abaixo ou igual ao VMP em águas potáveis, de 1,0 $\mu \mathrm{g} \cdot \mathrm{L}^{-1}$. Assim como concluíram Müller, Raya-Rodriguez \& Cybis (2009), esse resultado era esperado, tendo em vista que a concentração inicial de toxina nos experimentos $\left(\approx 100 \mu \mathrm{g} . \mathrm{L}^{-1}\right)$ é elevada em comparação com os valores típicos de florações $\left(<50 \mu \mathrm{g} . \mathrm{L}^{-1}\right)$. No entanto, a relação entre o decaimento de MC-LR e o aumento de carvão em solução (Figura 5) possibilitou a estimativa dosagem de CA teórica, necessária para atingir o VMP da Portaria de Consolidação n 5/2017 (BRASIL, 2017) (Tabela 4).

Em relação à variação do $\mathrm{pH}$ após a adsorção, observou-se uma tendência de aumento em todos os casos em função da dosagem de CA (Figura 5). Os valores de $\mathrm{pH}$ correspondentes à dosagem de $0 \mathrm{mg} . \mathrm{L}^{-1}$ estiveram entre 7,00-7,44. Já para as máximas dosagens de CA, os valores após a adsorção aumentaram, especialmente para o CGHU: 7,51 (CGLIN), 8,03 (CGHU), 7,41 (CGCO1 e CGCO2), 7,48 (CGCO3), 7,60 (CGCO4) e 7,8 (CGMAC) (Figura 5). Os dados obtidos sugerem que o pH após a adsorção foi mais influenciado pela água de estudo (com

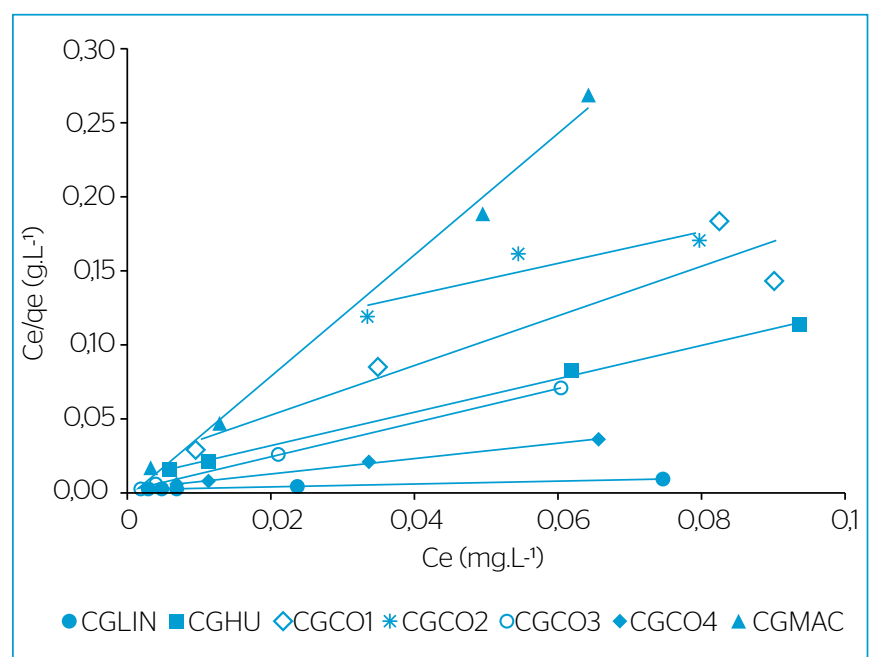

Figura 4 - Ajuste dos dados de adsorção de microcistina-LR ao modelo de Langmuir.

Tabela 3 - Ajuste do ensaio de adsorção de microcistina-LR pelos carvões ativados aos modelos de Freundlich e Langmuir.

\begin{tabular}{|c|c|c|c|c|c|c|c|c|c|c|c|}
\hline \multirow[b]{2}{*}{ Carvão } & \multirow[b]{2}{*}{$C_{o}\left(\mu g \cdot L^{-1}\right)$} & \multirow[b]{2}{*}{ TE (h) } & \multirow{2}{*}{$\begin{array}{c}\text { Dosagem } \\
\left.\text { máxima (mg. } \mathrm{L}^{-1}\right)\end{array}$} & \multirow{2}{*}{$\begin{array}{l}C_{e, \min } \\
\left(\mu \mathrm{g} \cdot \mathrm{L}^{-1}\right)\end{array}$} & \multirow{2}{*}{$\begin{array}{l}\text { Remoção } \\
\text { (\%) }\end{array}$} & \multicolumn{3}{|c|}{ Freundlich } & \multicolumn{3}{|c|}{ Langmuir } \\
\hline & & & & & & $\mathrm{K}_{\mathrm{ad}}\left(\mathrm{L} \cdot \mathrm{g}^{-1}\right)$ & $1 / n$ & $\mathrm{R}^{2}$ & $\begin{array}{c}\mathrm{q}_{\mathrm{e}, \max } \\
\left(\mathrm{mg} \cdot \mathrm{g}^{-1}\right)\end{array}$ & $\begin{array}{c}\mathrm{b} \\
\left(\mathrm{L} \cdot \mathrm{mg}^{-1}\right)\end{array}$ & $\mathrm{R}^{2}$ \\
\hline CGLIN & 115,1 & 4 & 100,0 & 3,2 & 97 & 702,8 & 0,59 & 0,968 & 10,56 & 41,17 & 0,981 \\
\hline $\mathrm{CGHU}$ & 154,9 & 4 & 375,0 & 5,7 & 96 & 289,8 & 0,23 & 0,926 & 0,86 & 148,83 & 0,997 \\
\hline CGCO1 & 137,7 & 2 & 375,0 & 9,5 & 93 & 29,4 & 0,93 & 0,742 & 0,60 & 85,15 & 0,882 \\
\hline CGCO2 & 137,7 & 2 & 375,0 & 33,3 & 76 & 1,1 & 1,51 & 0,856 & 0,93 & 11,76 & 0,817 \\
\hline CGCO3 & 81,9 & 2 & 125,0 & 1,9 & 98 & 645,5 & 0,07 & 0,818 & 0,66 & 1519,00 & 0,999 \\
\hline CGCO4 & 154,9 & 1 & 125,0 & 7,0 & 96 & 902,2 & 0,17 & 0,923 & 1,89 & 240,73 & 0,999 \\
\hline CGMAC & 81,9 & 2 & 375,0 & 3,3 & 96 & 176,2 & 0,15 & 0,664 & 0,24 & 385,67 & 0,995 \\
\hline
\end{tabular}

TE: tempo de equilíbrio; $C_{\text {emin }}$ : concentração mínima encontrada após uso da dosagem máxima de carvão ativado. 


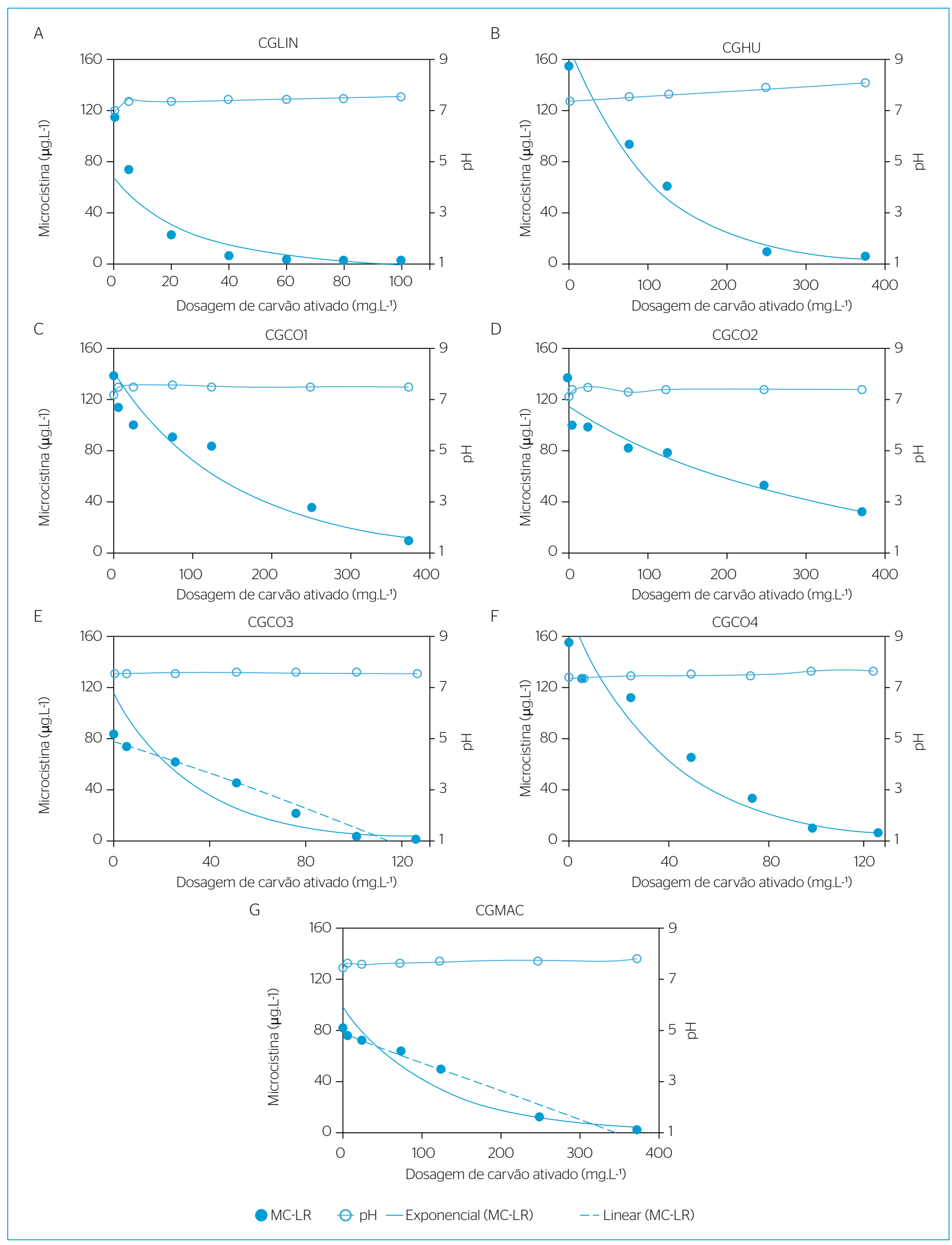

Figura 5 - Ajuste do decaimento da microcistina-LR em função da dosagem dos carvões ativados. 
Tabela 4 - Ajuste dos dados aos modelos linear e exponencial para estimativa da dosagem de carvão ativado teórica para atingir o valor máximo permitido de microcistina pela Portaria de Consolidação no 5/2017 (BRASIL, 2017).

\begin{tabular}{|c|c|c|c|c|c|c|}
\hline \multirow{2}{*}{ Carvão } & \multicolumn{3}{|c|}{ Linear } & \multicolumn{3}{|c|}{ Exponencial } \\
\hline & Equação & $\mathrm{R}^{2}$ & $\mathrm{D}^{*}\left(\mathrm{mg} \cdot \mathrm{L}^{-1}\right)$ & Equação & $\mathrm{R}^{2}$ & $D^{*}\left(m g \cdot L^{-1}\right)$ \\
\hline CGLIN & - & - & - & $y=65,48 . e^{-0.037 x}$ & 0,877 & 113,0 \\
\hline CGHU & - & - & - & $y=169,48 \cdot e^{-0,009 x}$ & 0,976 & 570,3 \\
\hline CGCO1 & - & - & - & $y=137,86 . e^{-0,006 x}$ & 0,950 & 821,1 \\
\hline CGCO2 & - & - & - & $y=113,95 \cdot e^{-0.003 x}$ & 0,950 & 1578,3 \\
\hline CGCO3 & $y=-0,674 . x+77,79$ & 0,975 & 113,9 & $y=113,87 . e^{-0,03 x}$ & 0,923 & 157,8 \\
\hline CGCO4 & - & - & - & $y=177,61 . e^{-0.025 x}$ & 0,967 & 207,2 \\
\hline CGMAC & $y=-0,218 . x+77,89$ & 0,968 & 352,8 & $y=97,07 . e^{-0,008 x}$ & 0,964 & 572,0 \\
\hline
\end{tabular}

y: concentração de microcistina residual ( $\mu$ g. $\left.L^{-1}\right)$; $x$ : dosagem de carvão ativado (mg. $\left.L^{-1}\right)$; $D^{*}$ : dosagens de carvão ativado estimadas pelas equações de regressão para se atingir concentração residual de 1,0 $\mu \mathrm{gMC}$-LR.L'․․

Tabela 5 - Correlação linear de Pearson ( $r$ ) entre os parâmetros de caracterização e as constantes da isoterma de adsorção de microcistina-LR.

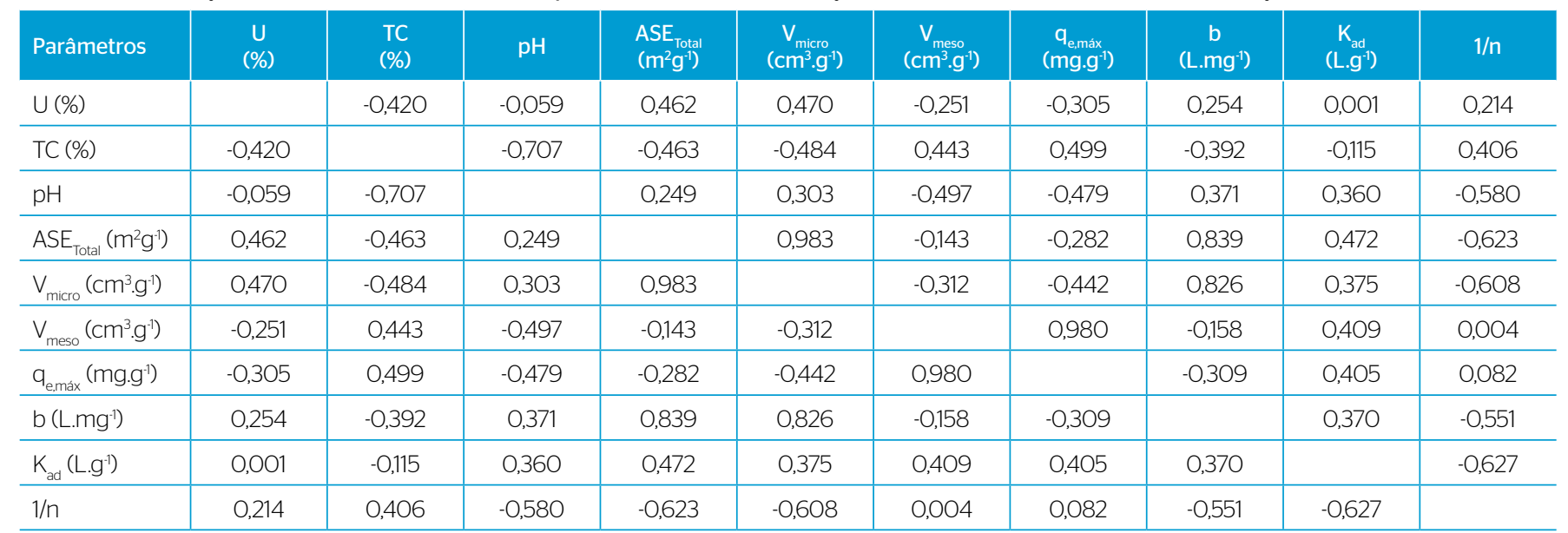

a microcistina) e pelas concentrações remanescentes da toxina com as diferentes dosagens de CA aplicadas. A influência do pH de origem dos carvões ativados, obtidos na etapa de caracterização geral (Figura 1), pareceu ser menos importante, já que os carvões apresentaram amplas variações de $\mathrm{pH}$ inicial (de caráter mais ácido a mais básico), mas, após exposição à água de estudo nos ensaios de adsorção, a maioria dos valores de $\mathrm{pH}$ estiveram próximos à faixa 7-8 (Figura 5).

$\mathrm{O}$ pH e a força iônica da solução são importantes para os ensaios de adsorção (MOHAMED et al., 1999). Na presente pesquisa, o pH apresentou faixa relativamente estreita de variação (7-8) na tentativa de reproduzir o que ocorreria em ETA sem a necessidade de adição de produtos químicos, diferentemente de outros estudos (por exemplo, pH entre 4,4-6,4 e 2,5-6,5 nos estudos de Lee (2009) e Pendleton, Schumann \& Wong (2001), respectivamente). Assim, no caso do presente estudo e das condições testadas, o $\mathrm{pH}$ provavelmente apresentou menor influência em relação a outros fatores porque a molécula de MC possui caráter hidrofóbico e pequeno número de grupos funcionais ionizáveis.

A menor dosagem da amostra do CGLIN necessária para atingir

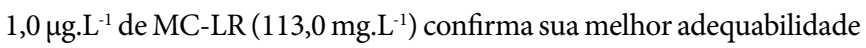

para remoção de MC-LR entre os carvões estudados. Assim como relatado no trabalho de Donati et al. (1994), pelo coeficiente de Pearson (Tabela 5), encontrou-se correlação positiva significativa ( $r=0,980)$ entre $\mathrm{q}_{\mathrm{e} \text {,máx }}$ e o $\mathrm{V}_{\text {meso }}$. Isso indica que a adsorção das moléculas de MC-LR dependeu da predominância de mesoporos. Pendleton, Schumann \& Wong (2001) também verificaram uma correlação linear $(r=0,93)$ entre $\mathrm{V}_{\text {meso }}$ e a capacidade de adsorção de MC-LR estudando carvões ativados de madeira e casca de coco.

Outros autores relataram que a presença de microporos secundários (GUERRA et al., 2015) ou mesoporos (HUANG, CHENG \& CHENG, 2007) foi decisiva para a capacidade adsortiva da toxina por CAG. Além de microporos e mesoporos disponíveis para a adsorção, Wang et al. (2007) ressaltaram a importância da biodegradação como mecanismo complementar de remoção da MC em filtros de CAG pela formação de biofilme com microrganismos aptos a metabolizar o poluente.

Observou-se correlação positiva entre $\mathrm{V}_{\text {micro }}$ e a ASE $(r=0,983)$ e a constante de Langmuir $(\mathrm{b})(\mathrm{r}=0,826)$. Isso indica que a microporosidade do carvão influencia a energia da adsorção, segundo Langmuir, e contribui para a formação da ASE do material ativado. Correlação negativa 
foi observada entre o pH e o TC (r=-0,707). Observou-se ausência de correlação linear entre $\mathrm{K}_{\mathrm{ad}}$ e umidade $(\mathrm{U})(\mathrm{r}=0,001)$, enquanto a força da ligação entre adsorvato-adsorvente $(1 / \mathrm{n})$ não apresentou correlação com $\mathrm{V}_{\text {meso }}(\mathrm{r}=0,004)$.

\section{CONCLUSÕES}

A comparação do desempenho dos CAG produzidos a partir de diferentes matérias-primas para a adsorção de MC-LR de águas de abastecimento por meio de testes laboratoriais permitiu concluir:

- Com relação aos dados obtidos na fase de caracterização, os valores de umidade foram influenciados pela matéria-prima dos CAG. As variações do TC e do $\mathrm{pH}$ também estiveram associadas ao processo produtivo, além das características da matéria-prima. A maioria das amostras apresentou estrutura essencialmente microporosa. A amostra produzida a partir de casca de macadâmia (CGMAC) satisfez aos critérios de umidade, TC e $\mathrm{ASE}_{\text {total }}$, estabelecidos pela norma AWWA B604/12 para a aplicação de CAG no tratamento de água. Contudo, esse carvão apresentou desempenho insatisfatório na adsorção de MC-LR. Isso reforça que, embora uma amostra de CAG possa ser considerada adequada ao tratamento segundo os limites estabelecidos em norma, testes de adsorção com o poluente-alvo são imprescindíveis;

- Os dados de seis dos sete carvões se ajustaram melhor ao modelo de Langmuir nos ensaios de adsorção de MC-LR $\left(R^{2}>0,88\right)$. Segundo esse modelo, o carvão produzido a partir de linhito mostrou a maior capacidade adsortiva (remoção máxima de 97\% de MC-LR para uma concentração inicial de 115,1 $\mu \mathrm{g}$. $\mathrm{L}^{-1}$ ). Esse carvão apresentou maior volume de mesoporos, o que permite concluir que este é um parâmetro fundamental que influencia na determinação da capacidade adsortiva de MC-LR. Destacou-se ainda a capacidade de adsorção de um dos carvões de casca de coco, possivelmente como resultado da sua elevada $\operatorname{ASE}_{\text {total }}\left(1.184 \mathrm{~m}^{2} \cdot \mathrm{g}^{-1}\right)$;

- Com o agravamento das condições sanitárias das bacias hidrográficas e o comprometimento da qualidade da água dos mananciais, cada vez mais sujeitos a florações de cianobactérias, estratégias para a remoção de cianotoxinas da água devem ser aprimoradas. Espera-se que os dados gerados nesta pesquisa ofereçam subsídios para estudos de tratabilidade em ETA com vistas à remoção de MC por adsorção com carvão ativado.

\section{REFERÊNCIAS}

ALBUQUERQUE JÚNIOR, E.C.; MÉNDEZ, M.O.; COUTINHO, A.R.; FRANCO, T.T. (2008a) Efeito da estrutura porosa de carvões ativados sob a cinética de adsorção de microcistinas em processo batelada. In: SIMPÓSIO LUSO-BRASILEIRO DE ENGENHARIA SANITÁRIA E AMBIENTAL, 13., 2008. Anais... Belém: ABES, p. 1-11.

ALBUQUERQUE JÚNIOR, E.C.; MÉNDEZ, M.O.; COUTINHO, A.R.; FRANCO, T.T. (2008b) Remoção de contaminantes orgânicos tóxicos presentes em água por meio de adsorção em carvão ativado. In: SIMPÓSIO LUSO-BRASILEIRO DE ENGENHARIA SANITÁRIA E AMBIENTAL, 13., 2008. Anais... Belém: ABES, p. 1-9.

ALBUQUERQUE JÚNIOR, E.C:; MÉNDEZ, M.O;; COUTINHO, A.R.; FRANCO, T.T. (2008c) Removal of cyanobacteria toxins from drinking water by adsorption on activated carbon fibers. Materials Research, v. 11, n. 3, p. 371-380. http://dx.doi.org/10.1590/S151614392008000300023

AMERICAN SOCIETY FOR TESTING AND MATERIALS (ASTM). (2014) D 3860: Standard Practice for Determination of Adsorptive Capacity of Activated Carbon by Aqueous Phase Isotherm Technique. West Conshohocken. cap. 16.

ASSOCIAÇÃO BRASILEIRA DE NORMAS TÉCNICAS (ABNT). (1991a) EB 2.133 (NBR 11.834): Carvão ativado pulverizado. Rio de Janeiro: ABNT.

(1991b) MB 3.414 (NBR 12.077): Carvão ativado pulverizado: determinação da umidade. Rio de Janeiro: ABNT.
BRADY, R.; MORAN, M. (2012) Activated Carbon Adsorption. In: STEPHEN, J.R.; HORSLEY, M.B. (Eds.). Water Treatment Plant Design. 5. ed. Nova York: McGraw-Hill.

BRASIL. (2011) Portaria de Consolidação no 5, de 28 de setembro de 2017. Dispõe, entre outros, sobre os procedimentos de controle e de vigilância da qualidade da água para consumo humano e seu padrão de potabilidade. Diário Oficial [da] República Federativa do Brasil, Brasília.

CALIJURI, M.C.; ALVES, M.S.A.; SANTOS, A.C.A. dos. (2006) Cianobactérias e Cianotoxinas em Águas Continentais. São Carlos: RiMa. $118 \mathrm{p}$

CAMPINAS, M.; ROSA, M.J. (2006) The ionic strength effect on microcystin and natural organic matter surrogate adsorption onto PAC. Journal of Colloid and Interface Science, v. 299, n. 2, p. 520 529. https://doi.org/10.1016/j.jcis.2006.02.042

CARMICHAEL, W.W. (2000) Assessment of blue-green algal toxins in raw and finished drinking water. Dayton: AWWA Research Foundation and American Water Works Association. 208 p.

CARMICHAEL, W.W.; AZEVEDO, S.M.; AN, J.S.; MOLICA, R.J.; JOCHIMSEN, E.M.; LAU, S.; RINEHART, K.L.; SHAW, G.R.; EAGLESHAM, G.K. (2001) Human fatalities from cyanobacteria: Chemical and biological evidence for cyanotoxins. Environmental Health Perspectives, v. 109, n. 7, p. 663-668. 
CHORUS, I. (2001) Introduction: Cyanotoxins - Research for Enviromental Safety and Human Health. In: CHORUS, I. (Org.). Cyanotoxins: occurence, causes and consequences. Berlim: Springer. p. 1-14.

COSTA, F.O.; SILVA, A.M.; CARVALHO, E.S.; SILVA, V.L.M.M.; LIMA, L.M.R. (2012) Uso da casca da banana como bioadsorvente em leito diferencial na adsorção de compostos orgânicos. In: ENCONTRO NACIONAL DE CIÊNCIA, EDUCAÇÃO E TECNOLOGIA, 1., 2012. Anais... Campina Grande: UEPB. p. 1-8.

DI BERNARDO, L.; DANTAS, A.D.B. (2005) Métodos e técnicas de tratamento de água. 2. ed. São Carlos: RiMa. v. 2. 792 p.

DONATI, C.; DRIKAS, M.; HAYES, R.; NEWCOMBE, G. (1994) Microcystin-LR adsorption by powdered activated carbon. Water Research, v. 28, n. 8, p. 1735-1742. https://doi.org/10.1016/00431354(94)90245-3

DURIGAN, M.A.B.; VAZ, S.R.; PERALTA-ZAMORA, P. (2012) Degradação de poluentes emergentes por processos fenton e foto-fenton. Química Nova, v. 35, n. 7, p. 1381-1387. http://dx.doi. org/10.1590/S0100-40422012000700018

GIANNUZZI, L.; SEDAN, D.; ECHENIQUE, R.; ANDRINOLO, D. (2011) An acute case of intoxication with cyanobacteria and cyanotoxins in recreational water in Salto Grande Dam, Argentina. Marine Drugs, v. 9, n. 11, p. 2164-2175. https://dx.doi.org/10.3390\%2Fmd9112164

GUERRA, A.B.; TONUCCI, M.C.; CEBALLOS, B.S.O.; GUIMARÃES, H.R.C.; LOPES, W.S.; AQUINO, S.F.; LIBÂNIO, M. (2015) Remoção de microcistina-LR de águas eutrofizadas por clarificação e filtração seguidas de adsorção em carvão ativado granular. Engenharia Sanitária e Ambiental, v. 20, p. 603-612. http://dx.doi.org/10.1590/ S1413-41522015020040108649

HARKE, M.J.; STEFFEN, M.M.; GOBLER, C.J.; OTTEN, T.G.; WILHELM, S.W; WOOD, S.A.; PAERL, H.W. (2O16) A review of the global ecology, genomics, and biogeography of the toxic cyanobacterium, Microcystis spp. Harmful Algae, v. 54, p. 4-20. https://doi.org/10.1016/j. hal.2015.12.007

HENA, S.; ISMAIL, N.; ISAAM, A.M.; AHMAD, A.; BHAWANI, S.A. (2O14) Removal of microcystin-LR from aqueous solutions using \% burnoff activated carbon of waste wood material. Journal of Water Supply: Research and Technology - AQUA, v. 63, n. 5, p. 332-341. https://doi.org/10.2166/aqua.2013.256

HILBORN, E.D.; SOARES, R.M.; SERVAITES, J.C.; DELGADO, A.G.; MAGALHÃES, V.F.; CARMICHAEL, W.W.; AZEVEDO, S.M.F.O. (2O13) Sublethal Microcystin Exposure and Biochemical Outcomes among Hemodialysis Patients. PLoS One, v. 8, n. 7, p. 1-9. https://doi. org/10.1371/journal.pone.0069518

HUANG, W.J.; CHENG, B.L.; CHENG, Y.L. (2007) Adsorption of microcystin-LR by three types of activated carbon. Journal of Hazardous Materials, v. 141, n. 1, p. 115-122. https://doi.org/10.1016/j. jhazmat.2006.06.122

JAPANESE INDUSTRIAL STANDARD (JIS). (2014) K 1474: Test methods for activated carbon. Tóquio: JIS.
KURODA, E.K.; ALBUQUERQUE JR., E.C.; BERNARDO, L.Di; TROFINO, J.C. (2005) Caracterização e escolha do tipo de carvão ativado a ser empregado no tratamento de águas contendo microcistinas. In: CONGRESSO BRASILEIRO DE ENGENHARIA SANITÁRIA E AMBIENTAL, 23., 2005. Anais... Rio de Janeiro: ABES. p. 1-10.

LAMBERT, T.W.; HOLMES, C.F.B.; HRUDEY, S.E. (1996) Adsorption of microcystin-LR by activated carbon and removal in full scale water treatment. Water Research, v. 30, n. 6, p. 1411-1422. https://doi. org/10.1016/0043-1354(96)00026-7

LEE, J.J. (2009) Removal of microcystin-LR from drinking water using adsorption and membrane processes. 170 f. Tese (Doutorado em Engenharia Civil) - Universidade Estadual de Ohio, Columbus.

LETTERMAN, R.D. (Org.). (1999) Water Quality and Treatment: A Handbook of Community Water Supplies. 5. ed. Estados Unidos: McGraw-Hill. 1163 p.

MARTINEZ, M.S.; PIZA, A.V.T; DANTAS, A. Di B.; PASCHOALATO, C.F.P.R.; BERNARDO, L. Di (2011) Remoção dos herbicidas diuron e hexazinona de água por adsorção em carvão ativado. Revista DAE, v. 59, p. 35-39. https://doi.org/10.4322/dae.2014.071

MARTINS, J.C.; VASCONCELOS, V.M. (2009) Microcystin dynamics in aquatic organisms. Journal of Toxicology and Environmental Health, Part B, v. 12, n. 1, p. 65-82. https://doi. org/10.1080/10937400802545151

MÉNDEZ, M.O.A.; LISBÔA, A.C.L.; COUTINHO, A.R.; OTANI, C. (2006) Activated petroleum coke for natural gas storage. Journal of the Brazilian Chemical Society, v. 17, n. 6, p. 1144-1150. http://dx.doi. org/10.1590/S0103-50532006000600011

MOHAMED, Z.A.; CARMICHAEL, W.W.; AN, J.; EL-SHAROUNY, H.M. (1999) Activated carbon removal efficiency of microcystins in an aqueous cell extract of Microcystis aeruginosa and Oscillatoria tenuis strains isolated from Egyptian freshwaters. Environmental Toxicology, v. 14, n. 1, p. 197-201. https://doi.org/10.1002/(SICI)15227278(199902)14:1\%3C197::AID-TOX25\%3E3.0.CO;2-6

MÜLLER, C.C.; RAYA-RODRIGUEZ, M.T.; CYBIS, L.F. (2009) Adsorção em carvão ativado em pó para remoção de microcistina de água de abastecimento público. Engenharia Sanitaria e Ambiental, v. 14, n. 1, p. 29-38.

ORTOLAN, A.V.S. (2016) Adsorção com carvão ativado granular e degradação biológica para o tratamento avançado de águas de abastecimento: remoção de microcistina em escala laboratorial. 94 f. Dissertação (Mestrado em Ciências) - Departamento de Hidráulica e Saneamento, Escola de Engenharia de São Carlos, Universidade de São Paulo, São Carlos.

PENDLETON, P.; SCHUMANN, R.; WONG, S.H. (2001) Microcystin-LR adsorption by activated carbon. Journal of Colloid and Interface Science, v. 240, n. 1, p. 1-8. https://doi.org/10.1006/jcis.2001.7616

PETERS, N.E.; MEYBECK, M. (2000) Water Quality Degradation Effects on Freshwater Availability: Impacts of Human Activities. Water International, v. 25, n. 2, p. 185-193. https://doi. org/10.1080/02508060008686817 
REALI, M.A.P.; SABOGAL-PAZ, L.P.; DANIEL, L.A. (2013) Tratamento de água para consumo humano. In: CALIJURI, M.C.; CUNHA, D.G.F. (Orgs.). Engenharia Ambiental: conceitos, tecnologia e gestão. Rio de Janeiro: Elsevier. p. 405-454.

REYNOLDS, T.D.; RICHARDS, P.A. (1995) Unit Operations and Process in Environmental Engineering. 2. ed. Boston: PWS Publishing Company. p. 350-375.

RODRIGUES, L.A.; SILVA, M.L.C.P.; MENDES, M.O.A.; COUTINHO, A.R.; THIM, G.P. (2011) Phenol removal from aqueous solution by activated carbon produced from avocado kernel seeds. Chemical Engineering Journal, v. 174, n. 1, p. 49-57.

SAUVÉ, S.; DESROSIERS, M. (2014) A review of what is an emerging contaminant. Chemistry Central Journal, v. 8, n. 15, p. 1-7. https://doi. org/10.1186/1752-153X-8-15

SING, K.S.W.; EVERETT, D.H.; HAUL, R.A.W.; MOSCOU, L.; PIEROTTI, R.A.; ROUQUÉROL, J.; SIEMIENIEWSKA, T. (1985) Reporting physisorption data for gas/soils systems with special reference to the determination of surface area and porosity. Commission on Colloid and Surface Chemistry Including Catalysis, Physical Chemistry Division, International Union of Pure and Applied Chemistry (IUPAC). Pure Applied Chemistry, v. 57, n. 4, p. 603-619.

TEIXEIRA, M.G.L.C.; COSTA, M.C.N.; CARVALHO, V.L.P.; PEREIRA, M.S.; HAGE, E. (1993) Epidemia de gastroenterite na área da Barragem de Itaparica, Bahia. Boletín de la Oficina Sanitaria Panamericana, v. 114, n. 6, p. 502-512.

TÖRÖKNÉ, A.; ASZTALOS, M.; BÁNKINÉ, M.; BICKEL, H.; BORBÉLY, G.; CARMELI, S.; CODD, G.A.; FASTNER, J.; HUANG, Q.; HUMPAGE, H.; METCALF, J.S.; RÁBAI, E.; SUKENIK, A.; SURÁNYI, G.; VASAS, G.; WEISZFEILER, V. (2004) Interlaboratory comparison trial on cylindrospermopsin measurement. Analytical Biochemistry, v. 332, n. 2, p. 280-284. https://doi.org/10.1016/j.ab.2004.05.036
UNITED STATES ENVIRONMENTAL PROTECTION AGENCY (USEPA). (2014) Cyanobacteria and Cyanotoxins: Information for Drinking Water Systems. 11 p. Disponível em: <https://www.epa. gov/sites/production/files/2014-08/documents/cyanobacteria factsheet.pdf>. Acesso em: 25 set. 2015.

WANG, H.; HO, L.; LEWIS, D.M.; BROOKES, J.D.; NEWCOMBE, G. (2OO7) Discriminating and assessing adsorption and biodegradation removal mechanisms during granular activated carbon filtration of microcystin toxins. Water Research, v. 41, n. 18, p. 4262-4270. https:// doi.org/10.1016/j.watres.2007.05.057

WOOD, R. (2016) Acute animal and human poisonings from cyanotoxin exposure: a review of the literature. Environment International, v. 91, n. 10, p. 276-282. https://doi.org/10.1016/j. envint.2016.02.026

WORLD HEALTH ORGANIZATION (WHO). (2011) Guidelines for Drinking-water Quality. 4. ed. Genebra: WHO Library Cataloguingin-Publication Data.

YILMAZ, M.; PHLIPS, E.; SZABO, N.; BADYLAK, S. (2008) A comparative study of Florida strains of Cylindrospermopsis and Aphanizomenon for cylindrospermopsin production. Toxicon, v. 51, n. 1, p. 130-139. https://doi.org/10.1016/j.toxicon.2007.08.013

ZAGO, J.F. (2010) Influência das características físico-químicas de carvões ativados na adsorção de saxitoxinas. 202 f. Tese (Doutorado em Tecnologia Ambiental e Recursos Hídricos) - Departamento de Engenharia Civil e Ambiental, Faculdade de Tecnologia da Universidade de Brasília, Brasília.

ZHU, S.; YIN, D.; GAO, N.; ZHOU, S.; WANG, Z.; ZHANG, Z. (2016) Adsorption of two microcystins onto activated carbon: equilibrium, kinetic, and influential factors. Desalination and Water Treatment, v. 57, n. 17, p. 23666-23674. https://doi.org/10.108 O/19443994.2015.1137492 